\title{
A TRAVEL BEHAVIOR ANALYSIS OF URBAN CYCLING FACILITIES IN MONTRÉAL CANADA
}

\author{
Jacob Larsen and Ahmed El-Geneidy ${ }^{*}$ \\ School of Urban Planning, McGill University, Montréal, Canada
}

Please cite this article in press as: Larsen, J., \& El-Geneidy, A. (2011). A travel behavior analysis of urban cycling facilities in Montréal Canada. Transportation Research Part D: Transport and Environment, 16 (2), 172-177.

\begin{abstract}
This study examines the personal factors that influence cycling facility usage and how specific facility types and their spatial characteristics affect route choice. This study is based on an online survey of 2,917 cyclists from Montreal, Quebec, Canada. Respondent's most frequent home-based trips are modeled using a geographic information system. Several statistical models are used to measure the cycling patterns associated with different types of utilitarian cyclists. Experienced cyclists are less likely to use cycling facilities compared to other kinds of cyclists. Overall, cyclists add greater distance to their trips for facilities that are segregated from vehicle traffic, however, this additional diversion distance is best explained by facility length and supply of nearby facilities.
\end{abstract}

Keywords: Active transportation, Cycling, Travel Behaviour, Route choice

\section{INTRODUCTION}

Concerns over traffic congestion, climate change and harmful consequences of sedentary lifestyles have led to the efforts of encouraging cycling as a mainstream mode of transportation. It has become accepted among urban planners, transportation specialists and public health officials that cycling facilities are a key component to encouraging cycling and active lifestyles, however, little is known about what types of facilities that can best achieve these goals. There is however limited understanding of the factors that influence the decision to use a cycling facility and how specific facility types and their spatial characteristics affect cyclist's travel distance and route choice.

We conduct a highly detailed analysis of the use of on-street and off-street cycling facilities in Montreal, Quebec, Canada. Montreal includes a variety of on-street and offstreet facilities, and an established series of bidirectional, on-street "sidepaths", making it a good location to compare use of different facility types. In contrast to other studies that tend to be restricted to individual facilities or population groups, the approach integrates origin-destination information and specific routes reported by cyclists, allowing for an examination of the factors affecting routes choices. For Montreal, understanding the distinct travel patterns associated with various facility types is important, especially given plans to double the existing cycling infrastructure by 2020 (Ville de Montréal, 2008).

\section{DATA AND SURVEY}

\footnotetext{
${ }^{*}$ Corresponding Author: ahmed.elgeneidy@mcgill.ca
} 
The primary source of data is derived from an online survey conducted in Montreal during summer 2009 involving 2917 respondents. Respondents provided information on the location of their home and primary bicycle destination, the cycling path used, if any, the times of year they cycle, and information on trip purpose. This trip-related data is complemented by demographic and socioeconomic information, as well as cyclists' selfclassification of their cycling profile. To counter the self-selection bias that has been linked to online surveys, various outreach methods were used, including: three local newspapers in English and French, several urban issues blogs, various online newsletters and mailing lists, various social networking sites, email forwards and physical flyers distributed to cyclists at cycling events and on local cycling facilities. This variety of techniques for survey dissemination is recommended by Dillman et al. (2009) to compensate for biases in online surveys.

While no large North American city can be compared with the levels of utilitarian cycling achieved in many European centers, Montreal is generally regarded as a North American leader. The Island of Montreal has $425 \mathrm{~km}$ of cycling facilities, comprising 264 $\mathrm{km}$ off-street and $161 \mathrm{~km}$ on-street. The official mode share of cycling for Montreal is $1.3 \%$ of all trips (Pucher and Buehler, 2006), which is around the national average, however central areas are between 6-7\% (Vélo-Québec, 2005). Additional data is derived from geographic information systems (GIS) files of the Montreal region, detailing roads, current bicycle routes, recorded bicycle crashes and other physical features.

Respondents' home and primary destinations were geo-coded in GIS, as well the locations where the access and egress points for the primary cycling facility used. This was performed in using the Network Analyst in ArcGIS 9.3 by calculating the shortest path between the respondent's home and the closest intersection on the bicycle facility indicated, and likewise to their destination. These four points were used to analyze the most salient details about the respondents reported trip, including the hypothetical shortest distance from home to destination, their distance travelled on a bicycle facility, the actual distance of the respondents' trip and the difference between the shortest and actual distances.

\section{RESULTS}

Distance decay functions provide a relatively simple tool for understanding the spatial distribution of travel behavior. The concept has been used to compare distances traveled to transit stops (Taylor, 1975, Zhao et al., 2003) and by bicycle to use off-street facilities (Krizek et al., 2007). In this study, we use distance decay to examine a hypothetical distance: the difference between the respondent's actual route taken and their shortest possible route. Given the focus on utilitarian cycling, only trips made for non-recreational purposes were used (1,302 trips). Decay curves were generated for 1,302 trips that used cycling facilities, $12 \%$ of these occurred along off-street facilities, while $64 \%$ took place on on-street sidepaths and $22 \%$ of the reported trips that used a facility used an on-street striped lane. Examining the decay curve (Figure 1), one notes that more cyclists will travel farther to use off-street facilities than all other facility types; likewise, cyclists travel farther to use separated on-street facilities than those delineated by road paint alone. 


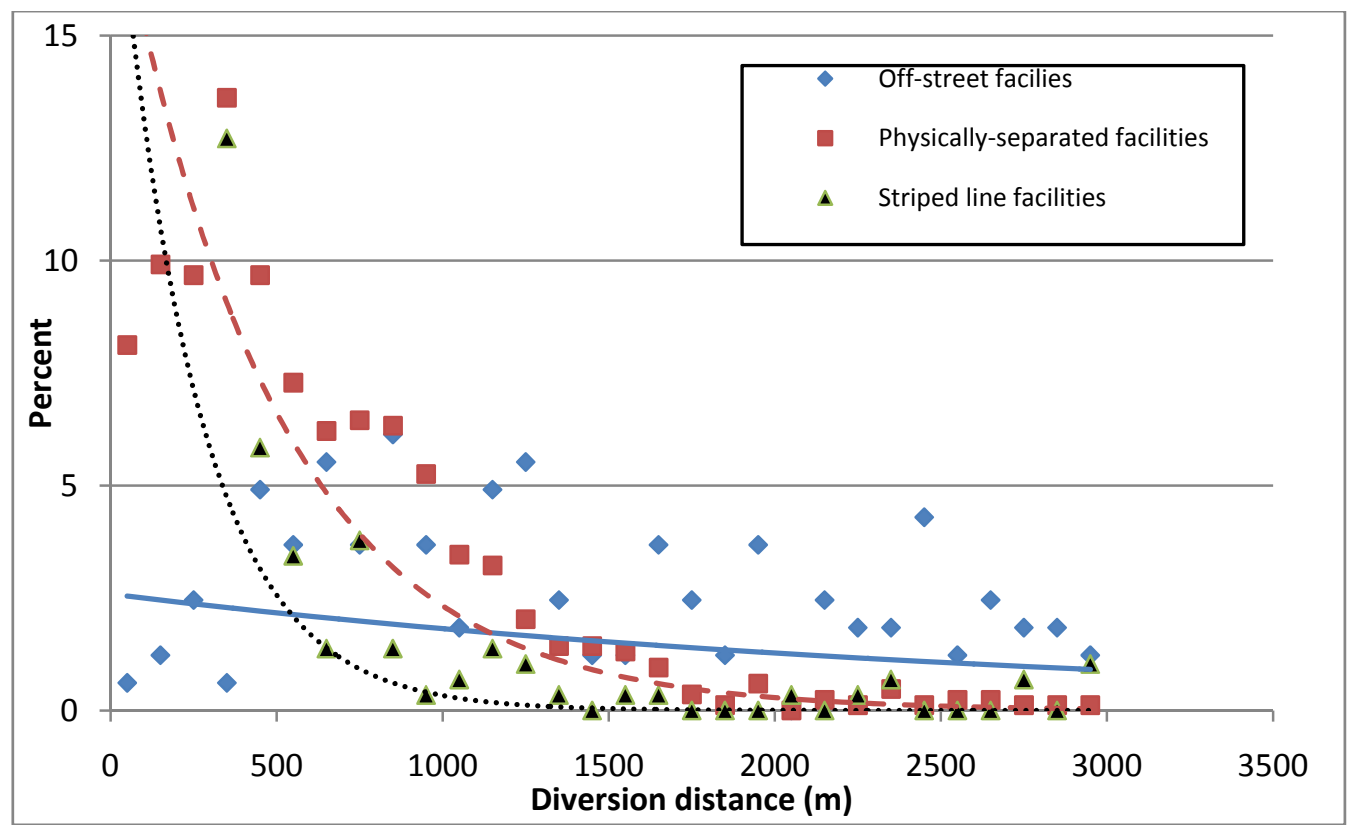

Figure 1: Distance decay of diversion distances by facility type

Evaluating facilities based solely on diversion distances, however, ignores other spatial factors such as facility length. Examining specific facility lengths, off-street facilities tend to be longest, followed by on-street sidepaths and on-street striped lanes, with diversions closely related with facility length. Overall, the Pearson correlation between the length of a given facility and the associated diversion distance is 0.84, suggesting that facility length has a direct effect on the additional distance cyclists will add to their journey to use it. To develop a more thorough understanding the effects of other spatial factors such as facility length on cyclist travel behavior, we turn now to an analysis of the statistical models of all reported trips.

To better explain the factors that influence a cyclist's decision to use a bicycle facility and increase diversion distances when a facility is used, four models are applied. In the first, a binary logit model tests the likelihood of a respondent using a bicycle facility for all respondents for whom full data are available $(\mathrm{N}=1811)$. The other models are a series of ordinary least square regressions, which examine trip distance and diversion distance. The first of these models consists of two parts (Models 1a and b) and takes the route distance as the dependent variable. Model 1a examines the effect of facility usage in general on travel distance, while $1 \mathrm{~b}$ highlights the effects of specific facility types. Model 2 excludes non-facility users $(\mathrm{N}=1393)$ and seeks to explain the diversion distances introduced in the previous section. A summary of the variables used is provided in Table 1. 
Table 1: Summary statistics

Variables

Respondent characteristics

Age of respondent

Respondent is male

History of accident

Uses a bicycle occasionally, in good conditions

Uses a bicycle regularly, in average conditions

Uses a bicycle frequently, in all conditions

Trip characteristics

Used a bicycle path

Used an off-street facility

Used an on-street, physically-separated facility

Used an on-street facility, marked with a painted line

Actual trip length $(\mathrm{km})$

Shortest route $(\mathrm{km})$

Shortest route (ln)

Distance on facility $(\mathrm{km})$

Other facilities within $400 \mathrm{~m}$ of path segment $(\mathrm{km})$

Difference between actual \& shortest routes $(\mathrm{km})$

Distance from home to CBD $(\mathrm{km})$

Presence of facility within $400 \mathrm{~m}$ of home and destination

Number of bike accidents per $\mathrm{km}$ on shortest path

Number of intersections per km on shortest path

Number of auto destinations per km on shortest path

Difference in bike accidents per km (actual - shortest)

Difference in intersections per km (actual - shortest)

Destination is in CBD

Trip made for work purpose
Mean Std.dev Min Max Model

\begin{tabular}{ccccl}
34.88 & 10.77 & 14.00 & 81.00 & $\mathrm{~L}, 1 \mathrm{a}, 1 \mathrm{~b}, 2$ \\
0.59 & 0.49 & 0.00 & 1.00 & $\mathrm{~L}, 1 \mathrm{a}, 1 \mathrm{~b}, 2$ \\
0.37 & 0.48 & 0.00 & 1.00 & $\mathrm{~L}$ \\
0.15 & 0.35 & 0.00 & 1.00 & $\mathrm{~L}, 1 \mathrm{a}, 1 \mathrm{~b}, 2$ \\
0.52 & 0.50 & 0.00 & 1.00 & $\mathrm{~L}, 1 \mathrm{a}, 1 \mathrm{~b}, 2$ \\
0.27 & 0.45 & 0.00 & 1.00 & $\mathrm{~L}, 1 \mathrm{a}, 1 \mathrm{~b}, 2$ \\
& & & & \\
0.69 & 0.46 & 0.00 & 1.00 & $1 \mathrm{a}$ \\
0.09 & 0.28 & 0.00 & 1.00 & $1 \mathrm{~b}, 2$ \\
0.44 & 0.50 & 0.00 & 1.00 & $1 \mathrm{~b}, 2$ \\
0.16 & 0.37 & 0.00 & 1.00 & $1 \mathrm{~b}, 2$ \\
6.43 & 5.00 & 0.03 & 39.93 & $1 \mathrm{~b}, 2$ \\
5.91 & 4.50 & 38.34 & 33.77 & $1 \mathrm{~b}, 2$ \\
8.43 & 0.76 & 3.65 & 10.43 & $\mathrm{~L}$ \\
2.26 & 2.67 & 0.00 & 17.37 & 2 \\
12.89 & 13.97 & 0.00 & 54.97 & 2 \\
0.53 & 0.94 & 0.00 & 10.93 & 2 \\
6.04 & 4.41 & 0.00 & 36.03 & $1 \mathrm{a}, 1 \mathrm{~b}, 2$ \\
0.48 & 0.50 & 0.00 & 1.00 & $\mathrm{~L}, 1 \mathrm{a}, 1 \mathrm{~b}$ \\
8.61 & 5.85 & 0.00 & 57.79 & $\mathrm{~L}$ \\
42.63 & 14.05 & 11.20 & 417.33 & $\mathrm{~L}$ \\
219.39 & 154.71 & 9.58 & 3182.16 & $\mathrm{~L}$ \\
4.82 & 5.24 & 0.00 & 56.86 & 2 \\
130.57 & 142.84 & 0.00 & 986.22 & 2 \\
0.48 & 0.50 & 0.00 & 1.00 & $\mathrm{~L}$ \\
0.69 & 0.46 & 0.00 & 1.00 & $\mathrm{~L}, 2$ \\
\hline & & & & \\
\hline
\end{tabular}

L=Logit model

Table 2 shows the results of the binary logit model, which identifies the factors that increase a cyclist's odds of using a bicycle facility. Examining the statistically significant variables, the natural log of the length of a cyclist's journey had the strongest effect on the odds of taking a facility. This logarithmic function shows that a cyclist making a $1 \mathrm{~km}$ trip is on average $90 \%$ more likely to use a facility than on a $500 \mathrm{~m}$ trip, whereas a cyclist making a $1.5 \mathrm{~km}$ trip is only $10 \%$ more likely to use a facility than on 1 $\mathrm{km}$ trip; this is logical given that incremental trip distance increases to short trips greatly increases the chance of encountering a facility.

Other spatial factors affecting facility usage are having a destination in the CBD, which was shown to increase the odds of using a facility by $45 \%$, and having a bicycle facility within 400 meters of both home and destination, which increases the odds of facility usage by $129 \%$. We hypothesized that three route-specific variables relating to the hypothetical shortest path would increase the odds of diverting from that path to use a facility: the number of reported bicycle crashes per km; the number of intersections per $\mathrm{km}$; and the number of automobile destinations reported in the Montreal regional OriginDestination survey (Agence métropolitaine de transport, 2003) within a 50 meter buffer 
of the respondents shortest path (as a proxy for exposure to motor vehicles). Of these three variables, an increase in bicycle crashes on a cyclist's shortest path was shown to increase odds of using a facility by $5 \%$. While the ratio is small, this likely indicates that cyclists accurately perceive relative danger and alter their routes accordingly. Conversely, a greater density of intersections, and the number of car destinations within a 50 meter buffer of the respondent's shortest path were statistically significant, but had little effect on respondents' probabilities of using a facility.

Table 2: Logit model

\begin{tabular}{lcc}
\hline Variable & Odds ratio & $z$ \\
\hline Shortest path (ln) & $1.84 * * *$ & 4.96 \\
Age of respondent & 0.99 & -1.42 \\
Respondent is male & 0.92 & -0.70 \\
History of accident & 0.87 & -1.12 \\
Destination is in CBD & $1.45^{* * *}$ & 3.06 \\
Number of bike accidents per km on shortest path & $1.05^{* * *}$ & 4.06 \\
Number of intersections per km on shortest path & $0.99 *$ & -1.78 \\
Number of auto destinations per km on shortest path & $1.01^{* * *}$ & 3.68 \\
Cycling facility within 400m of both origin and destination & $2.29 * * *$ & 6.77 \\
Respondent uses a bicycle occasionally, in good conditions & 0.51 & -1.46 \\
Respondent uses a bicycle regularly, in average conditions & $0.37 * *$ & -2.30 \\
Respondent uses a bicycle frequently, in all conditions & $0.31^{* * *}$ & -2.64 \\
Trip made for work purpose & 1.09 & 0.67 \\
\hline Log likelihood & -995.3223 \\
LR chi ${ }^{2}$ & 263.74 \\
N & \multicolumn{2}{c}{1811} \\
Dependent variable & Facility usage \\
\hline ignificant at the 99\% level, **significant at the 95\% level, *significant at the $90 \%$ level
\end{tabular}

Personal characteristics such as self-reported cycling profiles are shown to have a more significant effect on facility usage. Relative of those who ride only recreationally, respondents who use a bicycle regularly for utilitarian purposes in average conditions are $64 \%$ less likely to use a facility; those who ride frequently in all conditions are $69 \%$ less likely to use a facility, while no statistically significant difference in probability of facility usage was noted for occasional cyclists. Several other variables, while failing to reach levels of statistical significance, were shown to have some effect on the likelihood of taking a path, including a history of a bicycle crash and trips made for work purposes. Interestingly, age and gender did not have a statistically significant impact on facility usage, contradicting past research on gender and cycling (Garrarda et al., 2008, Dill and Gliebe, 2008).

Three ordinary least squares regression estimates which were run to explore the effect of personal and spatial characteristics on distance traveled for non-recreational cycling trips; these models are shown in table 3 . Models $1 \mathrm{a}$ and $1 \mathrm{~b}$ take trip distance as the dependent variable; Model 1a examines the effect on distance of using a cycling facility, while Model 1b isolates the specific effect of various cycling facilities on distance. Model 2 includes only those cyclists who used a facility, isolating the effect of 
specific facilities. Beginning with the statistically significant variables, Model 1a reveals that cyclists who used a facility added, on average, $2.2 \mathrm{~km}$ (34\%) to their trip distance. When specific facility types are included in Model $1 \mathrm{~b}$, we see that relative to non-facility users, those who used off-street facilities added an average of $4.6 \mathrm{~km}$ (71\%) to their trips and those who used physically-separated, on-street facilities added an average of $2 \mathrm{~km}$ (31\%) to their trips. The use of on-street striped lanes increased the distance relative to non-facility users by $1.6 \mathrm{~km}$ (25\%). Not surprisingly, an increase of $1 \mathrm{~km}$ between the respondent's home and the CBD (defined as the spatial average of all respondents' destinations) increases the trip distance by $680 \mathrm{~m}$. However, the presence of a bicycle facility within $400 \mathrm{~m}$ of both home and destination had the effect of decreasing trip distance by about $800 \mathrm{~m}(12 \%)$, an intuitive finding given the concentration of cycling facilities in central areas, where travel distances tend to be shorter. Like the positive relationship found between work trips and facility usage, work trips added on average one $\mathrm{km}(16 \%)$ more to the trip length.

Examining the statistically significant variables in Model 2, in which the diversion distance is used as the dependent variable, reveals that when variables related to the chosen facility are controlled for, different facility types have a diminished effect on diversion distance. Relative to on-street striped lanes, respondents added $1 \mathrm{~km}(16 \%)$ to use off-street facilities and the diversion difference between on-street sidepaths and onstreet striped lanes is negligible. The length of facilities within 400 meters of the taken route has a statistically negative effect on diversion distances, resulting in an average decrease in the diversion distance by $4.5 \mathrm{~m}$ for every meter of nearby facilities, keeping all other variables at their mean values. This observation draws a direct connection between the supply of cycling facilities the demand for a specific facility, measured by diversion distance. Additionally, we see that an increase by $1 \mathrm{~km}$ traveled using a facility produces an additional $200 \mathrm{~m}$ in diversion distance; this explains the correlation between facility length and mean diversions, since longer facilities permit greater distances to be traveled. Examining the variables related to cyclist characteristics, we note only one with a statistically significant relationship with trip distance or diversion distance. Occasional cyclists, who report using a bicycle for shorter journeys with fewer adverse conditions, on average travel $1.2 \mathrm{~km}(19 \%)$ shorter distances than recreational cyclists. This finding is not surprising, given the fitness motivation that likely influences much recreational cycling. Age and gender were not shown to have a statistically significant relationship on either trip or diversion distances. 
Table 3: OLS regression models

\begin{tabular}{|c|c|c|c|}
\hline \multirow{2}{*}{ Variables } & Model 1a & Model 1b & Model 2 \\
\hline & Coefficient & Coefficient & Coefficient \\
\hline Constants & -1246.66 & -826.97 & -45.26761 \\
\hline Age of respondent & 66.21 & 46.30 & 2.94 \\
\hline Respondent is male & 158.93 & 123.91 & -27.29 \\
\hline Uses a bicycle occasionally, in good conditions & $-1271.42 * *$ & $-1103.60 * *$ & 35.17 \\
\hline Uses a bicycle regularly, in average conditions & -6.51 & 198.82 & 35.31 \\
\hline Uses a bicycle frequently, in all conditions & 322.75 & 418.60 & 13.89 \\
\hline Used a bicycle path & $2182.91 * * *$ & -- & -- \\
\hline Facility: off-street & -- & $4577.34^{* * *}$ & $1005.99 * * *$ \\
\hline Facility: on-street, physically-separated & -- & $1991.18^{* * *}$ & $-99.33 * *$ \\
\hline Facility: on-street, painted line & -- & $1587.94 * * *$ & -- \\
\hline Distance on facility & -- & -- & $0.21 * * *$ \\
\hline Other facilities within $400 \mathrm{~m}$ of path segment (m) & -- & -- & $-4.49 * * *$ \\
\hline Distance from home to CBD & $0.68^{* * *}$ & $0.67 * * *$ & 0.003 \\
\hline Facility within $400 \mathrm{~m}$ of home and destination & $-791.36 * * *$ & $-824.57 * * *$ & -- \\
\hline Work trip & $1093.91 * * *$ & $1051.34^{* * *}$ & -- \\
\hline Difference in bike accidents per km & -- & -- & $-11.57 * * *$ \\
\hline Difference in intersections per km & -- & -- & $15.61^{* * *}$ \\
\hline $\mathrm{R}^{2}$ & 0.5058 & 0.5286 & 0.5368 \\
\hline $\mathrm{N}$ & 1812 & 1812 & 1393 \\
\hline Dependent variable & $\begin{array}{l}\text { Distance of route } \\
\text { traveled (1) }\end{array}$ & $\begin{array}{l}\text { Distance of route } \\
\text { traveled (2) }\end{array}$ & $\begin{array}{l}\text { Difference (actual } \\
\text { route - shortest) }\end{array}$ \\
\hline \multicolumn{4}{|c|}{$* * *$ significant at the $99 \%$ level, **significant at the $95 \%$ level, *significant at the $90 \%$ level } \\
\hline \multicolumn{4}{|c|}{$\begin{array}{l}\text { To illustrate the effects of various facility types on trip distance among different } \\
\text { cyclist types; we perform a sensitivity analysis by multiplying the coefficients from } \\
\text { Model 1b with the mean values of the independent values contained therein. This } \\
\text { provides a picture of average trip distances associated with three cyclist types, on various } \\
\text { facility types, assuming the following conditions are met: the trip is for work purposes, } \\
\text { the respondent is male and a facility is within } 400 \mathrm{~m} \text { of both the respondent's origin and } \\
\text { destination. Assessing each incremental investment in cycling facilities between no } \\
\text { facility and off-street facilities, the greatest increases in trip distance are associated with } \\
\text { off-street facilities, while the smallest increase occurs between on-street painted lines and } \\
\text { on-street separated facilities. }\end{array}$} \\
\hline
\end{tabular}




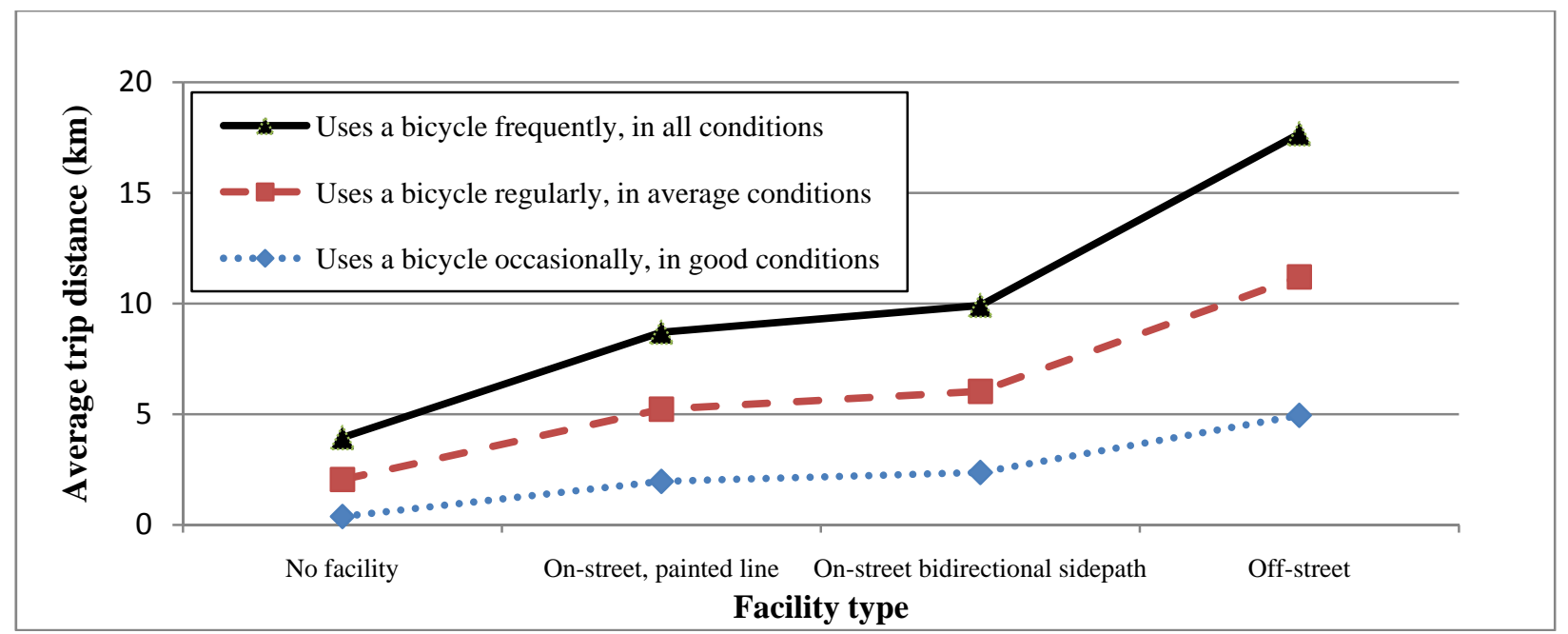

Figure 1: Sensitivity analysis of Model 1b: Total trip distance

\section{CONCLUSION}

This study finds recreational cyclists are most likely to use bicycle facilities, while occasional, regular and frequent cyclists are less likely to, with frequent cyclists on average traveling greater distances than others. Likewise, greater separation from vehicle traffic through off-street or physically-separated sidepaths is shown to positively affect trip distance. Examining the additional distance traveled to use various facilities, the effects of facility types is not so straightforward. When factors such as the length of the chosen facility and the presence of other nearby facilities are controlled for, the apparent preference for on-street sidepaths is no longer observed. Diversion distance to a given facility is best explained by the supply of nearby facilities. Moreover, the distance traveled on a given facility has a considerable effect on the diversions that cyclists are willing to make. Other route-level characteristics were shown to have an effect on the likelihood of using a facility and the extent to which a cyclist will divert from their shortest path. The number of reported bicycle crashes on a respondent's shortest route increased the likelihood of a respondent using a facility, while the difference in the number of crashes and the difference in the number of car destinations did not.

The results raise several important issues regarding bicycle facility design and location for transportation professionals. On the one hand, the preference for physicallyseparated facilities among more infrequent cyclists suggests that this facility design is the obvious choice in encouraging new and novice cyclists. Complicating matters, though, the distance traveled on a facility and the availability of other facilities was observed to nullify the difference in diversions between various on-street facilities. As transportation professionals weigh the increased capital costs of physically-separated sidepaths against less expensive bicycle lane marking options, they may be forced to decide between a more attractive option and a more efficient one. In such a case, widespread implementation of longer, continuous cycling facilities may ultimately attract more users.

\section{ACKNOWLEDGMENTS}

We would like to thank David Brown, McGill University for his helpful comments on an earlier version of this manuscript. The authors would also like to thank all the Montreal cyclists who completed the 2009 McGill Cycling Survey for their thoughtful responses. 
We would like to thank Daniel Bergeron of the Agence métropolitaine de transport providing the detailed Montréal 2003 O-D survey. Thanks also to members of the Transportation Research at McGill (TRAM) team for their help with the survey and their suggestions on the analysis, and the two anonymous reviewers for their constructive feedback. Last but not least we would like to thank Prof. Ken Button for his help and input during the review process. Funding was provided by The Natural Science and Engineering Research Council of Canada, Social Science and Humanities Research Council, and the Canada Foundation for Innovation.

\section{REFERENCES}

Agence métropolitaine de transport AGENCE MÉTROPOLITAINE DE TRANSPORT 2003. Enquête origine-destination 2003. Montréal, QC.

DILL, J. \& GLIEBE, J. 2008. Understanding and measuring bicycling behavior: A focus on travel time and route choice. Oregon Transportation Research and Education Consortium (OTREC).

DILLMAN, D., SMYTH, J. \& CHRISTIAN, L. 2009. Internet, mail and mixed-mode surveys: The tailored design method, third edition, Hoboken, NJ, John Wiley and Sons, Inc.

GARRARDA, J., ROSEB, G. \& LO, S. 2008. Promoting transportation cycling for women: The role of bicycle infrastructure. Preventative Medicine, 46, 55-59.

KRIZEK, K., EL-GENEIDY, A. \& THOMPSON, K. 2007. A detailed analysis of how an urban trail system affects the travel of cyclists. Transportation, 34, 611-624.

PUCHER, J. \& BUEHLER, R. 2006. Why Canadians cycle more than Americans: A comparative analysis of bicycling trends and policies. Transport Policy, 13, 265-279.

TAYLOR, P. 1975. Distance decay models in spatial interactions, Norwich, UK, Geo Abstracts Ltd. VÉLO-QUÉBEC 2005. L'état du vélo au Québec en 2005. L'état du vélo au Québec. Montreal.

VILLE DE MONTRÉAL 2008. Plan de Transport. Montréal.

ZHAO, F., CHOW, L.-F., LI, M.-T., UBAKA, I. \& GAN, A. 2003. Forecasting transit walk accessibility: Regression model alternative to buffer. Transportation Research Record, 1835, 34-41. 